\title{
Alexandre Hardy, Alceste, ou la Fidélité (1624)
}

\section{Daniela Dalla Valle}

\section{(2) OpenEdition}

\section{Journals}

\section{Edizione digitale}

URL: http://journals.openedition.org/studifrancesi/34611

DOI: 10.4000/studifrancesi.34611

ISSN: 2421-5856

\section{Editore}

Rosenberg \& Sellier

\section{Edizione cartacea}

Data di pubblicazione: 1 novembre 2005

Paginazione: 410

ISSN: 0039-2944

\section{Notizia bibliografica digitale}

Daniela Dalla Valle, «Alexandre Hardy, Alceste, ou la Fidélité (1624)», Studi Francesi [Online], 146 (XLIX |

II) | 2005, online dal 30 novembre 2015, consultato il 19 avril 2021. URL: http://

journals.openedition.org/studifrancesi/34611 ; DOI: https://doi.org/10.4000/studifrancesi.34611

\section{Questo documento è stato generato automaticamente il 19 avril 2021.}

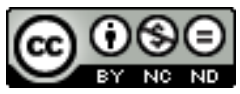

Studi Francesi è distribuita con Licenza Creative Commons Attribuzione - Non commerciale - Non opere derivate 4.0 Internazionale. 


\title{
Alexandre Hardy, Alceste, ou la Fidélité (1624)
}

\author{
Daniela Dalla Valle
}

\section{NOTIZIA}

ALEXANDRE HARDY, Alceste, ou la Fidélité (1624), éd. Par S. Léonide, préf. De B. Louvat-

Molozay, Toulouse, Société de Littératures Classiques, 2004, pp. 71.

1 Nella Collection de rééditions de textes du XVII siècle, esce ora quest'interessante riproposta di un'opera di Hardy, tragedia o tragicommedia: l'uso del termine è oscillante, sia nell'utilizzazione fatta nel testo, che li alterna tra la pagina del titolo e l'argomento, sia nel modo in cui le fonti utilizzate vengono elaborate. Si tratta di una rilettura del mito di Alcesti, pubblicata da Hardy nel 1624.

2 La prefazione ( $\mathrm{di}$ B. Louvat-Molozay) illustra brevemente la presenza del testo nell'insieme della produzione di Hardy, nel teatro contemporaneo e nella storia delle numerose riprese della stessa tematica nel teatro francese. L'introduzione (di S. Léonide) è più lunga e circostanziata, descrive dapprima puntualmente il posto di Alceste nella carriera di Hardy, la struttura di Alceste e l'uso delle fonti (Euripide e soprattutto Seneca, nell'Hercules furens), analizza poi la questione del genere - tragedia o tragicommedia - e commenta la funzione di Alceste fra la tragedia umanista e la tragedia spettacolare, per proporre - a livello conclusivo - una «lecture duelle» dell'Alceste, come lettura «tipologica» e lettura «simbolica».

3 Una bibliografia precede l'edizione, annotata; seguono un glossario e una breve appendice di annessi. 